\title{
The Missing Artistic Conception in Translating Chinese Classical Poems and Its Solutions
}

\author{
Zhihai Chen, Qingyan Li \\ Changchun Institute of Technology, Changchun, Jilin, China.
}

Keywords: The ancient Chinese poetry; translation; artistic conception: aesthetic study.

\begin{abstract}
Tthe artistic conception of ancient Chinese poetry is one of the main difficulties in poetry translation, and it is getting a hot debating topic for translators. Pro. Xu was inspired by other translators' theory and concluded his own practicing experience. Hence the Three Beauties theory was proposed. The Three Beauties theory refers to "beauty of sense, beauty of sound and beauty of form." The artistic conception missing has become a usual phenomenon. In order to solve this problem, this paper introduces Xu Yuanchong's three beauties theory. Thus it can demonstrate the feasible solution of avoiding artistic concept missing under the frame of aesthetic view. With demonstrating "the beauty in three aspects", this paper quotes some examples to make it clear that how the transference of aesthetic nature goes.
\end{abstract}

\section{The Aesthetic Features of Artistic Conception}

Knowing about the features of artistic conception is an sufficient way for understanding the artistic conception. This section mainly introduces its artistic characteristics. This may help readers to realize the vital role that it plays in poetry.

\subsection{Dynamic And Static Beauty}

In the field of philosophy, staticness and dynamicness are in contradiction. But in the poem, they Can be complementary and interchangeable. The staticness in the poem mirrors the calmness of the poet's mind and the dynamicness reflects his/her excitement. The combination or the change between staticness and dynamicness also reflects the poet's mental activity.

In the aesthetic domain of poetry appreciation, these two terms underlie each other, blending in dialectic harmony. Professor Gu Zheng yang (2006:76) once said "The depiction of dynamic and static scenes is one way to create the artistic conception of poetry Through the construction of dynamic and static images, and the artistic conception, not only can a poet produce clear and vivid scenes, but he also succeeds in revealing rich and complicated emotions."

It is unusual to see absolute staticness in a poem except landscape ones. The description of still images or emotions like homesickness and lovesickness etc. is staticness in a poem. In description of still scenery, poets often described outline of several images, instead of their specific features. In fact, the poets' truly implied thoughts were fully concealed by the apparent quiet scenery. The appreciation of such kind of poem is similar to appreciation of a painting in white and black. Under the superficial intonation lies profound beauty. Liu Zhongyuan’s poem Fishing in Snow (《江雪》)is a good example:

千山鸟飞绝, 万径人踪灭。孤舟蓑立翁, 独钓寒江雪。

This poem was written by Liu Zhongyuan when he was exiled to the southwest. It is considered a masterpiece of anchorite poem although it has only twenty words, but every word is concrete and makes an image. The first couplet begins with" a thousand mountains" and "ten thousand paths", which form a contrast not only with the bird and the footprint but also with the single boat and the lonely fisherman so that the solitude is accentuated. The snow provide a background which looks so cold and dreary that the cold-proof fisherman seems lonely and lofty, all the lonelier and loftier for he is fishing snow instead of fishing in snow. This old fisherman may be said to be the very picture of the lonely and high-hearted poet in exile. 


\subsection{Vacancy Beauty}

Vacancy is one of the most important concepts in the ancient Chinese poetry theories. It is no exaggeration to say that without understanding the concept of vacancy, or thoroughly researching into the status and function of vacancy in the ancient Chinese poetry, one cannot totally appreciate the aesthetic spirit of the ancient Chinese poetry from germ. Contemporary Chinese painter Li Keran says "vacancy and implication are a great learning in Chinese art." This is absolutely true to the ancient Chinese poetry. There are some other comments in the Chinese poetry theories which can be the proof. It is necessary for poetry not coming straight to the point. In order to keep the poetic flavor lingering, a poem should be ended where it seems to go on. To highlight the front, we can start from the back or side. The wisdom lies in that we know there is a rod when seeing is shadow.

Generally speaking, there are three features in the definition of vacancy: first, vacancy is not created without foundation, but is generated by the actual realm; second, the generation of vacancy is for the pursuit of aesthetic beauty; third, vacancy is a kind of virtual realm should be appreciated by the careful readers.

The ancient Chinese poetry pays much more attention to vacancy is due to its unique language forms. The ancient Chinese poetry is usually short and concise, yet a good poem should be rich in connotations. They cannot fill too many solids into the limited space. By leaving vacancy, a poet can use the fewest well chosen images to imply the best meaning beyond the words. According to the idea of reception aesthetics, understanding is a basic dialogue process carried out between readers and the text, and the meaning of the text is accomplished after the blend of readers' view with the view of the text during the process, so the meaning of the text is never ended or static but always open-ended and dynamic (Yang, 2009:16). Considering from this point, vacancy is not only the requisite of the language form of the ancient Chinese poetry, but also the requisite for readers to appreciate a piece of art.

\section{送 别}

下马饮君酒，问君何所之? 君言不得意，归卧南山陲。但去莫复问，白云无尽时。

This poem describes a picture of dialogue between the poet and his friend: The poet's friend is going to live in seclusion because he is tired of the secular world. At the end of the poem, the poet should have much to say, but he just mentions the endless clouds. The poem leaves a vacancy here. This vacancy gives readers much imagination space to experience the poet's emotion, which may be sympathy, consolation, lament, regret, admiration or more. Clouds Can easily be associated with hermit and freedom in Chinese culture. So the last line is closely related with the other lines and together they arouse readers' endless imagination. By the above analysis, it can be concluded that creativeness of vacancy in artistic conception is the performance of aesthetic essence, and it embodies the spirit of Chinese traditional poem philosophy. Vacancy manifestation in the translation of ancient Chinese poetry is the requisite to accurately transfer artistic conception, is the essential requirement of translation aesthetics.

\subsection{Harmony Beauty}

As the old saying goes, "Harmony is beauty” What's the harmony. Harmony is as what Dufrenne (1973)puts it "in every art, the sensuous must be arranged and ordered in such a way as to be perceived unequivocally." Harmony lies in the unequivocal organization, which refers to the integration of the separate parts. Maybe, it is very abstract in most of our mind. But as you look around: the grass and flowers aside the road are flirting in the slight wind. The sun, the glittering star and the moon are as a best companion in the sky on the night. Also, the sun in the morning is rising slowly from the skyline. The sea surface is getting brighter and glowing. And the peace pigeon is flying highly over the clouds in the sky. At that moment, you can understand what the real harmony is.

For the ancient Chinese poetry, harmony is essential for artistic conception. It concerns with the coordination of images and the choice of words symbolizing the images. Take two lines of Wang Wei’s poem On Mission to the Frontier (《使至塞上》) for example. “In boundless desert lonely 
smoke rises straight; over endless river the sun sinks round.” It seems unreasonable to describe smoke with "straight". But actually only "straight" can present the grandness of the lonely smoke. That will be fine with "the boundless desert" and "the endless river". The various images in a poem should be seen as a whole, and the poem should be understood as a unity of images not as listed different elements, thus obtains the intact image and overall artistic conception. Take Li Shangyin's poem Written on a Rainy Night to My wife in the North(《夜雨寄北》)for example:

夜雨寄北

君问归期未有期，巴山夜雨涨秋池。何当共剪西窗烛，却话巴山夜雨时。

This is a simple poem with just four sentences, the content is like this: you ask me when 1 will return, in fact I don't know. The autumn rain is falling day after day without ceasing. Bashan Mountain is in the dim light, and the pond is full. When can I trim candle wicks and talk with you again in the west window? When can we talk about this endless, dreary night of rain? The first two lines of the poem express the solitude, bitter and nostalgia of the poet in the strange land, and this emotion gets denser by the use of the two images - "rain" and "autumn". The last two lines are the imagination of the happiness for the future reunion (When by our window can we trim the wicks again, and talk about this endless, dreary night of rain?). In sum, this poem not only has described the poet's suffering of loneliness in the rainy night in Bashan Mountain, but also has imagined the happy and cheerful reunion in the future. The sadness at that time interwove with the future joy; the images of “巴山”, “夜雨”, “秋池”, “西窗” blend with each other, permeate in works as a whole.

In the ancient Chinese poetry translation, through the agency of harmony a translator can comprehend the whole poetic taste, and in the process of translation, he can create a text with a harmonious effect. As we know, word-for-word or sentence-for-sentence translation may not necessarily recreate the harmonious effect in the target text, as the source language and target language differ considerably in image-encoding. A text may be shorten or simplified, the elements of the poem and their fundamental coherence have to remain intact. and otherwise the work will lose its aesthetic identity as a whole.

\section{The Application of Xu Yuanchong'S “Three Beauties” in the Translation of Chinese Poetry}

The three beauties in theory refers to "beauty in sense", "beauty in sound", "beauty in form". The Three Beauties Theory quotes from Lu Xun's From words to Article, the original text goes as follows: "the beauty in sense touches your heart, the beauty in sound pleases your ear, the beauty in form inspires your eyes”. Mr. Lu uses this theory in article, while Xu Yuanchong practices this theory in translation, especially poetry translation.

After practicing poetry translation for so many years, professor Xu puts his literary translation theory in ten words: art of beautifulization and creation of the best as in rivalry (Xu Yuanchong, 2000;11-12). To some extent his Three Beauties Theory generated from Lu Xun's beauty in three aspects. He believes that poetry's literary qualities would be kept if they are translated in a good way. He also points out that keeping the original form is necessary because the Chinese poetry has strict regulation in rhyme and sentence which contributes a lot to convey the original meaning.

\subsection{The Beauty in Sense}

The beauty in sense means that the translated article is expected to convey the beauty of artistic conception or imagination originating from the original article. About this, Qian Zhongshu once puts forward a theory-emphasizes on sense and ignores form. "Emphasize on sense" means translation expresses original profound meaning. Xu Yuanchong thinks that "beauty in sense" sometimes caused by historical reason or imagination. When we translate one language to another language, the historical reason misses, and then imagination can't be aroused. And this causes translation to fail to express the beauty in sense. Therefore, not only should translator express literal meaning but also the implicit meaning. let’s appreciate this example: “人闲桂花落, 夜静春山空”. This line was translated like that, "I hear osmanthus blooms fall unenjoyed ; in still night hills dissolve into the 
void." The word "unenjoyed" implicit the conception of void. And "hear" indicates the peace in the valley.

Here the author would like to list another example to show how Mr.Xu's theory works in Chinese poetry translation. For example:

SL: 枫桥夜泊

月落乌啼霜满天, 江枫渔火对愁眠。

姑苏城外寒山寺, 夜半钟声到客船。

TL:

Mooring By Maple Bridge at Night

At moonset cry the crows, streaking the frosty sky.

Dimly lit fishing boats' neath maples sadly lie.

Beyond the city walls, from temple of cold hill,

Bells break the ship—-borne roamer's dream and midnight still

(Xu Yuanchong, 1996)

By comparing the original poem and the translated poem, we can find that in order to recreate the graceful conception of the original poem, Mr. Xu skillfully made use of the linguistic and cultural advantages of the target language to convey the beauty of the original poem. The sense of the poem is revealed in the whole of the translated poem, from the title to the text. This poem consists of three parts according to the sense. The first part is the title, the second is the first and second sentences, and the third is the other two sentences.

The title of the poem is short but connotative. Four characters have drawn the outline of a lively picture - in a quit night, a boat was anchored by the Maple Bridge. Mr. Xu uses the cultural meaning of the abundant vocabulary of the target language to reveal the sense of the original title, and one of the wonderful words is -mooring. In English culture, there are two meanings for mooring. One is verb, which means "anchor". The other is noun, which means "wilderness". Using this word could not only match with the “泊”, which means the anchored boat, but it also hints the solitary background of the original poem. The first and the second sentences are the enlargement and enhancement of the sense revealed in the title. The poet displays what he saw, what he heard and what he felt. All these made a further description to describe the night view and the Maple Bridge-the crying crows after the moon setting down, the frosty sky and cold river, the ancient bridge and dimly light and the lonely boat and the traveler. Hence the sense of loneliness could be expressed perfectly.

\subsection{The Beauty in Sound}

Language is an art of communication. It's not hard to find out that those nations who survive from countless wars and conflicts are bound to live with a beautiful language, like English, Chinese, French, etc. In people's daily life, language not only has to be spoken but also to be heard. And after language satisfying people's practical purpose, people began to make it more graceful and beautiful. Hence songs and poems flood in. Writers and poets try to create some works that sound like music by using rhyme. Thus, the beauty in sound means that translators should endeavor to present the beautiful sound of the original work, which includes meter, rhythm, alliteration and assonance, etc. Although there is some difference between Chinese and English in making rhyme, it's not impossible to realize this transformation. Let's appreciate an example:

SL:

自京赴奉先县咏怀

朱门酒肉臭, 路有冻死骨。荣枯迟尺异, 惆怅难再述。

TL: On the Way from the Capital to FengXian

The mansion burst with wine and meat,

The poor die frozen on the street.

Woe stands within an inch of weal,

Distressed, can I tell what I feel?

Each sentence of the original poem consists of five words. And each translated line corresponds with the original in eight syllables. The original poem is a free verse, while the translated poem is a blank verse, which rhymes with the form of “aabb”. Meanwhile, the translated lines have a nice 
alliteration-- The mansion burst with wine and meat; Woe stands within an inch of weal. Using alliteration not only generates a rhythm sensation but also a beauty of vision and hearing.

\subsection{The Beauty in Form}

And what is the beauty in form? It means the translated lines should be consistent with the original lines in length and structure. Mr. Xu pays a lot attention to the beauty in sound and form. Thus the translated version would keep the same rhythm and structure with the original poetry. He said, about the beauty in form, also the length and symmetry, its better that the two versions are similar, or they should be roughly similar at least. On the Height is a wonderful example for explaining this concept.

SL: 登鹳雀楼

TL:

$$
\text { 白日依山尽, 黄河入海流。欲穷千里目, 更上一层楼。 }
$$

The sun along the mountain bows, The yellow river seawards flows.

You can enjoy a greater sight, If you climb to a greater height.

On the stork tower is a famous five-character in China. The translated lines maintain the same sentence structure as the original one. Especially the first section, the original poem uses the pattern of 'subject + attribute + verb'. Apparently, the English version follows this pattern. In the first sentence, 'The sun' is subject, referring to ‘白日’. And 'along the mountains' refers to ‘依山'. 'bows' refers to '尽'. The second sentence uses a pattern of 'subject + adverbial + verb'. And it's amazing that the two versions correspond to each other perfectly since the sentence constituents lie in the same place.

\section{Conclusion}

About the connection and relationship between the three beauties, he once explained in his article published in the magazine the foreign language. He recons that the beauty in sense is vital, beauty in sound is minor and the beauty in form is least. In other words, one should express the beauty in sound in the condition that the beauty in sense has been conveyed. The beauty in form is expressed in condition that both the beauties in sense and sound are ensured. The beauty in sound and form are necessary condition, and the beauty in sense is necessary condition and sufficient condition. The beauty in sense is vital; the other two serve this purpose.

\section{Acknowledgements}

The authors would like to give their thanks to Changchun Institute of Technology(NO.320160034) for its financial and technical support.

\section{References}

[1]. Baker, Mona. In Other Words: A Course book on Translation[M]. Beijing: foreign language and research press, 2007.

[2]. Newmark, Peter. Approaches to Translation[M]. OxFord: Pergamon press,1981

[3]. Newmark, Peter. A textbook of Translation[M]. Shanghai Foreign Language Education Press, 2001.

[4]. Xu yuanchong. On Chinese Verse in English Rhyme[M]. Beijing: Peking University Press,1992:234

[5]. Xu Yuanchong. Song of the Immortals-an Anthology of Classical Chinese Poem[M]. Beijing: New World Press,1994. 